\title{
JUURNAL.RU
}

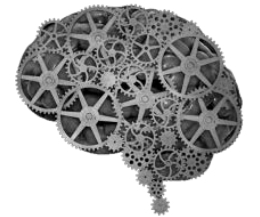

COMPANY GROUP "INTELLEKT"

\author{
Попова О.В. \\ Омский государственный университет им. Ф.М. Достоевского \\ Омск, Россия
}

doi: 10.18411/lj2016-6-3-07

\section{Полномочия сотрудников службы качества как мониторинговый показатель оценки системы управления проектами}

Публикация подготовлена в рамках поддержанного РГНФ научного проекта № 16-12-55010

Одной из наиболее важных функциональных областей управления проектами является область управления качеством, так как она напрямую связана с обеспечением необходимой степени соответствия совокупности характеристик проекта заявленным и подразумевающимся требованиям. Процесс управления качеством осуществляется на протяжении всех фаз жизненного цикла проекта и охватывает все его стороны и элементы, то есть взаимосвязан со всеми остальными функциональными областями управления. «Качество пронизывает весь проект и зависит от качества результатов всех процессов в проекте. Нарушение процессов в любой функциональной области, их несоответствие установленным критериям качества может повлиять на качество продукции проекта» [5, с. 121]. Поэтому, при разработке системы мониторинга эффективности управления проектами в компаниях необходимо использовать критерии, относящиеся к управлению качеством проектов. Одним из таких критериев является вовлеченность сотрудников службы качества в реализуемые проекты и общие бизнес-процессы организации, 
а также широта их полномочий на разных управленческих уровнях компании и стадиях жизненного цикла проектов.

При проведении мониторинга необходимо учитывать тот факт, что эффективно действующая корпоративная система управления проектами требует использования предприятием методов проектного управления на ряду с созданием современной системы менеджмента качества (СМК). Это накладывает некоторые специфические особенности на деятельность службы качества проектно-ориентированной компании.

Управление качеством должно иметь широкие и долговременные границы, представлять собой идеологию, действующую как в рамках проекта, так и за его пределами, в деятельности всей компании. В.В. Ильин отмечает, что, так как весь арсенал инструментов и методов управления качеством сосредоточен в рамках СМК, становится очевидным, что она должна распространить свое влияние на проекты, инициируемые и реализуемые организацией. Это означает, в частности, органичное интегрирование СМК в организационную структуру управления проектов и в первую очередь - в сферу управления качеством проектного продукта. Более того, она призвана в определенной степени реализовывать функции организационного «мозгового центра» для системы управления качеством проекта [4]. Таким образом, необходимо чтобы существующая в организации культура и технология управления качеством переносилась и на проект, находила свое отражения в планах качества проектов. Необходимость соблюдения этих условий требует определенной степени вовлечения сотрудников службы качества во все бизнес-процессы компании.

Для создания эффективно действующей системы менеджмента качества, ее постоянного совершенствования, полной интеграции с организационной структурой проектов, а также достижения более высокого уровня качества проектов, необходимо обеспечить:

- наличие четкой политики в области качества, понимание необходимости внедрения, функционирования и постоянного 
совершенствования общей системы менеджмента качества на всех уровнях управления организацией, начиная с высшего руководства и заканчивая рядовыми сотрудниками;

- позитивное отношение руководства к управлению качеством;

- лидерство менеджеров проектов в вопросах управления качеством;

- введение в команду проекта менеджера по качеству, наличие у него определенных полномочий и широкого круга компетенций, позволяющих осуществлять процедуры планирования, обеспечения и контроля качества в проектах, a также способствующих эффективной интеграции СМК родительской организации с организационной структурой проекта;

- наличие системы отбора персонала для включения в команду проектов;

- обеспечение подготовки и повышения квалификации персонала с целью достижения необходимой компетенции;

- включение в план проекта мероприятий по обучению участников команды проекта в области управления качеством;

- вовлеченность всех членов команды в процесс управления качеством проекта, поощрение и вознаграждение такого участия;

- настройка системы управления поставками, способствующей достижению и улучшению качества;

- наличие цели и инструментария постоянного улучшения проектов и их результатов (продуктов) на основе процессного подхода, системности, агрегирования лучшего опыта.

Выполнение этих условий требует создания ситуации, когда сотрудники службы качества, помимо выполнения функций напрямую связанных с управлением качества, имеют эффективные взаимосвязи с другими функциональными подразделениями проектно-ориентированной компании 
(материально-техническое обеспечение, маркетинг и др.) вовлекаются в деятельность проектного комитета, офиса управления проектами и оргструктуру отдельно взятого проекта. На рисунке 1 представлена мониторинговая модель вовлеченности сотрудников службы качества в бизнес-процессы проектноориентированной организации.

В результате технического, экономического и социального развития в последние десятилетия качество стало пониматься как управленческая задача уровня компании в целом. Размер службы качества обычно зависит от размера организации и специфики деятельности. По некоторым оценкам, в проектноориентированной организации служба качества составляет 1-5\% от общего числа сотрудников [6, с. 153]. Организационная культура должна позволять наладить эффективную связь между персоналом других подразделений компании и менеджерами по качеству, что было бы весьма полезно. Качество в общем понимании складывается из деятельности всех подразделений, и, чтобы сформировать мнение об их работе, менеджер по качеству должен обладать достаточными знаниями о ней. Для оказания значительного влияния на объективные показатели эффективности управления качеством, должны быть налажены сотрудничество и коммуникации между отделами. Возможно, менеджер по качеству должен обладать более полными знаниями о процессах организации, чем от него обычно требуют.

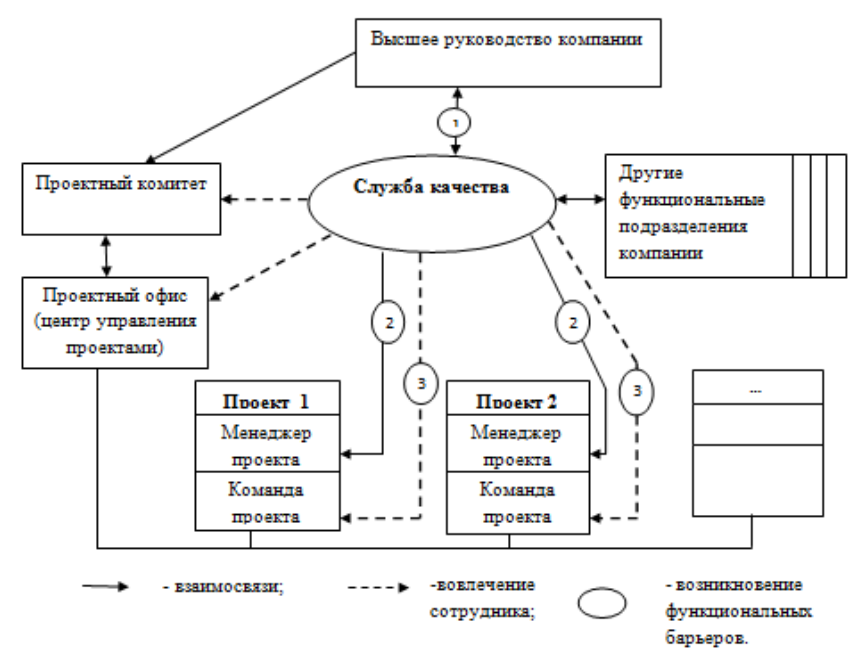

Рисунок 1. Мониторинговая модель вовлеченности сотрудников службы качества в бизнес-процессы проектно-ориентированной организации 
Параллельное внедрение или развитие двух областей деятельности: проектного управления и формировании эффективной системы менеджмента качества, требует преодоления неизбежно возникающих функциональных барьеров между персоналом организации. На рисунке обозначены три зоны возможного возникновения функциональных барьеров, которые можно также определить как зоны пересечения полномочий и ответственности, в которых происходит столкновение интересов сотрудников разных подразделений, связанных с выполнением ими своих функций и необходимостью их вовлечения в процессы управления качеством. Возможные способы преодоления подобных барьеров подробно рассмотрены автором в более ранних исследованиях [2].

Представленная модель показывает, что правильной является ситуация, когда руководитель подразделения, отвечающего за единую систему менеджмента качества родительской организации, а, следовательно, и за вопросы обеспечения качества отдельных проектов, входит в состав высшего руководства и занимает положение, равное положению руководителей других ее ведущих подразделений. Он должен являться членом совещательного органа, принимающего решения по проектам (Проектного комитета), так как вопросы авторизации проектов компании, определение их приоритетов, контроль по достижению целей проектов должен соответствовать стратегическим целям компании в области качества. Также сотрудники службы качества, несомненно, должны участвовать в тактическом и оперативном управлении проектами, то есть быть включенными в работу центра управления проектами (Проектного офиса). Такая ситуация является признанием серьезной роли качества в деятельности проектно-ориентированной организации. Перечислим возможные полномочия и функции сотрудника службы качества в:

1. В Проектном комитете: 
- участие в заседаниях, внесение в повестку дня вопросов, связанных с вопросами управления качеством;

- формирование с другими членами комитета общей политики компании в области качества;

- выдвижение инициатив по реализации проектов, направленных на формирование и совершенствование СМК;

- контроль соответствия авторизуемых проектов стратегическим целям компании в области качества.

2. В Проектном офисе:

- разработка общей методологии, инструментальное и организационное обеспечение процесса управления качеством в проектах;

- внедрение общей информационной системы планирования, мониторинга, формирования сводной отчетности по всем проектам компании в области управления их качеством.

Проектный менеджер по качеству должен тесно сотрудничать со всеми членами команды и координировать их деятельность в соответствии с требованиями СМК. Естественно, он не должен подменять членов команды, разбираться в различных технических вопросах лучше сотрудников специализированных служб, но ему необходимо понимать работу каждой функциональной области проекта, уметь находить слабые места в деятельности конкретных подразделений, а также выявлять наличие системных проблем и давать рекомендации по их устранению.

Таким образом, при мониторинге широты полномочий проектного менеджера по качеству нужно иметь ввиду, что диапазон его действий должен охватывать весь жизненный цикл проекта от его инициации (разработка и согласование требований стейкхолдеров) до передачи продукта проекта заказчику (конечный аудит и документ о соответствии продукта заявленным 
требованиям). Необходимо проверить наличие и степень выполнения у проектного менеджера следующих функций $[1,3,7]$ :

- формулирование и реализация принципов, целей и задач СМК родительской организации в рамках организационной структуры управления проектом и обеспечение этого интегрирования посредством установления и координации взаимосвязей между соответствующими управленческими блоками;

- участие в разработке и согласовании комплекса интересов стейкхолдеров $\mathrm{c}$ учетом приоритета требований заказчика (пользователя);

- организация и участие в текущем мониторинге и контроле качества процессов и работ проекта;

- организация и участие в промежуточных и конечном аудитах качества проекта;

- участие в администрировании контрактов с поставщиками проекта в части обеспечения и контроля качества поставок;

- участие в принятии решения о соответствии проектного продукта заявленным требованиям;

- участие в приемосдаточных испытаниях проектного продукта и передаче конечного продукта и комплекта сопроводительной документации заказчику (пользователю);

- формирование базы извлеченных уроков в области управления качеством проектов.

Также в процессе мониторинга систем управления проектами компаний необходимо проверить наличие системы показателей эффективности работы проектного менеджера по качеству, например: количество изменений в требованиях стейкхолдеров и спецификациях проекта, возникающих в процессе его выполнения; число существенных, документально оформленных изменений 
параметров процессов проекта за определенный период времени; количество пересмотров (ревизий) контрактов с поставщиками и др [3].

В настоящее время, благодаря признанию важности качества в целом, роль сотрудников службы качества значительно возросла и их вовлеченность в смежные бизнес-процессы проектно-ориентированной организации оказывает значительное влияние на эффективность системы управления проектами. 


\section{Список используемых источников информации}

1. Апенько С.Н., Попова О.В. Требования к персоналу проектов с позиций стандартов менеджмента качества. // Современный менеджмент: проблемы и перспективы. Материалы $\mathrm{X}$ международной научно-практической конференции 26-27 марта 2015 г. / СПб, Культ-информ-пресс, 2015. - С. 140-144.

2. Апенько С.Н., Попова О.В. Управление персоналом проекта и менеджмент качества: преодоление функциональных барьеров. // Кадровик. - 2015. -№ 9. - C. $44-51$

3. Даниляк В.И., Паскарис С.Е. О менеджменте качества проектов // Компетентность. - 2013. - № 3. - с.26-33.

4. Ильин В.В. Руководство качеством проектов. Практический опыт. - М.: Вершина, 2006. - 176 с.

5. Математические основы управления проектами: Учебное пособие [Текст] / С.А.Баркалов, В.И.Воропаев, Г.И. Секлетова и др. Под ред. В.Н. Буркова. М.: Высшая школа, 2005. - 423 с.

6. Молоткова Н.В., Сахаров И.С. Инфраструктура управления качеством ИТпроектов // Вопросы современной науки и практики. - 2008. - № 3(13). T.1. - c. $150-154$.

7. Тишков Ю.С. ISO 9001: Секреты успеха эффективной команды [Текст] / Ю.С.Тишков // Менеджмент качества. - 2012. - № 3. - с. 178-182. 